\title{
Implementasi Algoritma Backpropagation dalam Memprediksi Jumlah Mahasiswa Baru pada AMIK- STIKOM Tunas Bangsa Pematangsiantar
}

\author{
Indri Sriwahyuni Purba ${ }^{1}$, Dedy Hartama ${ }^{2}$, Ika Okta Kirana ${ }^{3}$ \\ ${ }^{1}$ Mahasiswa Program Studi Teknik Informatika, STIKOM Tunas Bangsa, Pematangsiantar \\ ${ }^{2}$ Dosen Program Studi Teknik Informatika, STIKOM Tunas Bangsa, Pematangsiantar \\ 123Jln. Sudirman Blok A No. 1, 2 dan 3 Pematangsiantar, 21117 \\ indrisriwahyunipoerba@gmail.com
}

\begin{abstract}
The number of new students at AMIK-STIKOM Tunas Bangsa Pematangsiantar greatly influences the improvement and development of available facilities both academically and non-academically. In this study, the author will conduct a prediction process on the object of new students which aims to determine the number of new students at AMIK-STIKOM Tunas Bangsa Pematangsiantar by applying the backpropagation learning algorithm. Backpropagation is one method on artificial neural networks that is quite reliable in solving problems including predictions. The study uses six (6) architectural models: 3-12-1, 3-13-1, 3-14-1, 3-15-1, 3-16-1, 3-18-1, from the six architectural models obtained the best architecture with 75\% accuracy, epoch 96 iterations in 1 second, namely architecture 3-16-1. The best architecture obtained is expected to be used as an illustration by the academic AMIK-STIKOM Tunas Bangsa in anticipating the development and increasing number of new students.
\end{abstract}

Keywords: AMIK-STIKOM, Prediction, Algorithm, Backpropagation, Students

Abstrak - Jumlah mahasiswa baru pada AMIK-STIKOM Tunas Bangsa Pematangsiantar sangat berpengaruh pada peningkatan dan perkembangan fasilitas yang tersedia baik akademik maupun non akademik. Pada penelitian ini, penulis akan melakukan proses prediksi terhadap objek mahasiswa baru yang bertujuan untuk mengetahui jumlah mahasiswa baru pada AMIK-STIKOM Tunas Bangsa Pematangsiantar dengan menerapkan algoritma pembelajaran backpropagation. Backpropagation merupakan salah satu metode pada jaringan syaraf tiruan yang cukup handal dalam menyelesaikan masalah termasuk prediksi. Penelitian menggunakan enam (6) model arsitektur : 3-12-1, 3-13-1, 3-14-1, 3-15-1, 3-16-1, 3-18-1, dari keenam model arsitektur tersebut diperoleh arsitektur terbaik dengan akurasi $75 \%$, epoch 96 iterasi dalam waktu 1 detik yaitu arsitektur 3-16-1. Arsitektur terbaik yang diperoleh ini diharapkan dapat digunakan sebagai gambaran oleh pihak akademik AMIK-STIKOM Tunas Bangsa dalam mengantisipasi perkembangan dan peningkatan jumlah mahasiswa baru.

Kata kunci: AMIK-STIKOM, Prediksi, Algoritma, Backpropagation, Mahasiswa

\section{PENDAHULUAN}

Perguruan tinggi merupakan satuan pendidikan yang menyelenggarakan pendidikan tinggi, penelitian dan pengabdian kepada masyarakat [1]. Perguruan tinggi dapat berbentuk akademi, politeknik, sekolah tinggi, institut, atau universitas. AMIK-STIKOM Tunas Bangsa merupakan 2 perguruan tinggi berbentuk akademi dan sekolah tinggi terakreditasi dalam satu yayasan yang ada di kotamadya Pematangsiantar, Sumatera Utara. Dikatakan demikian, AMIK Tunas 
Bangsa bertujuan untuk menyelenggarakan program pendidikan profesional dalam cabang teknologi dengan program studi Manajemen Informatika (MI) dan Komputerisasi Akuntansi (KA) dengan predikat akreditasi "B". Demikian halnya dengan STIKOM Tunas Bangsa yang bertujuan menyelenggarakan program pendidikan akademik atau profesional dalam satu displin ilmu komputer dan teknologi dengan program studi Sistem Informasi (SI) dan Teknik Informatika (TI) dengan akreditasi BAN-PT. Sebagai perguruan tinggi yang bergerak pada displin ilmu komputer dan teknologi, AMIK-STIKOM Tunas Bangsa merupakan salah satu perguruan tinggi yang diminati oleh kalangan muda yang ingin melanjutkan pendidikan ke jenjang yang lebih tinggi. Namun, tingginya minat untuk melanjutkan pendidikan ke perguruan tinggi ini dengan tingkat kelulusan siswa SMA/SMK yang diketahui berdasarkan data yang diperoleh bahwa terdapat 202 total jumlah sekolah menengah atas/kejuruan di kotamadya/kabupaten Sumatera Utara, AMIK-STIKOM Tunas Bangsa harus mampu menyeimbangkan dan meningkatkan segala faktor pendukung dengan faktor penghambat aktivitas kuliah baik secara akademik maupun non akademik. Salah satu faktor penghambat aktivitas kuliah yang apabila tidak diseimbangkan dengan fasilitas yang ada akan menyebabkan aktivitas yang berjalan menjadi kurang efektif adalah jumlah mahasiswa baru. Pada penerapannya, untuk mencapai kesuksesan aktivitas kuliah, AMIK-STIKOM Tunas Bangsa harus melakukan antisipasi terhadap keseimbangan jumlah mahasiswa baru dengan fasilitas yang ada.

Sehingga pada penelitian ini, penulis tertarik untuk melakukan proses prediksi terhadap jumlah mahasiswa baru pada AMIK-STIKOM Tunas Bangsa dengan menerapkan algoritma pembelajaran backpropagation yang bertujuan agar nantinya hasil yang diperoleh dapat digunakan sebagai gambaran oleh pihak akademik dalam mengantisipasi perkembangan dan peningkatan jumlah mahasiswa baru pada AMIK-STIKOM Tunas Bangsa Pematangsiantar. Algoritma backpropagation merupakan salah satu algoritma pada jaringan syaraf tiruan yang cukup handal dalam memecahkan masalah termasuk memprediksi suatu objek tertentu. Algoritma backpropagation merupakan salah satu sistem pemrosesan informasi yang didesain dengan menirukan cara kerja otak manusia dalam menyelesaikan suatu masalah dengan melakukan proses belajar melalui perubahan bobot sinapsisnya [2]-[4]. Pada penelitian ini, data yang digunakan diperoleh dari sistem informasi Penerimaan Mahasiswa Baru (PMB) setiap program studi AMIK-STIKOM Tunas Bangsa. Sumber data lima (5) tahun terhitung dari tahun 2014 sampai dengan 2018. Pada penelitian sebelumnya, dilakukan penelitian untuk melakukan perancangan perangkat lunak seleksi penerimaan calon mahasiswa baru dengan metode jaringan syaraf tiruan backpropagation". Berdasarkan hasil analisa yang ada, jaringan syaraf tiruan backpropagation cukup efektif digunakan untuk seleksi penerimaan calon mahasiswa. 


\section{METODOLOGI PENELITIAN}

\subsection{Pengumpulan Data}

Penelitian ini menggunakan data jumlah mahasiswa baru pada tahun 20142018 yang diperoleh melalui sistem informasi penerimaan mahasiswa baru (PMB) AMIK-STIKOM Tunas Bangsa Pematangsiantar.

\subsection{Algoritma Backpropagation}

Backpropagation merupakan algoritma pembelajaran yang terawasi dan biasanya digunakan oleh perceptron dengan banyak layar lapisan untuk mengubah bobot-bobot yang ada pada lapisan tersembunyinya. Algoritma backpropagation adalah algoritma iteratif yang mudah dan sederhana yang biasanya berkinerja baik, bahkan dengan data yang kompleks [5].

\subsection{Prediksi}

Prediksi adalah usaha menduga atau memperkirakan sesuatu yang akan terjadi di waktu mendatang dengan memanfaatkan berbagai informasi yang relevan pada waktu-waktu sebelumnya (historis) melalui suatu metode ilmiah [6][12]. Tujuan dari prediksi adalah mendapatkan informasi apa yang akan terjadi di masa datang dengan probabilitas kejadian terbesar.

\subsection{Mahasiswa Baru}

Mahasiswa merupakan suaru kelompok dalam masyarakat yang memperoleh status terkait dengan perguruan tinggi dengan batas usia sekitar 18-30 tahun [13]. Secara psikologis, mahasiswa baru masih berada pada posisi transformasi, fase antara remaja dan dewasa.

\subsection{Matlab}

Matlab adalah software buatan the mathwork inc, yang sangat bermanfaat untuk menyelesaikan berbagai masalah numerik, perangkat lunak ini menawarkan kemudahan dan kesederhanaan dalam menyelesaikan masalah yang berhubungan dengan vektor dan matriks [14].

\subsection{Kerangka Kerja Penelitian}

Kerangka penelitian kerja yang digunakan dalam menyelesaikan masalah penelitian ini. 


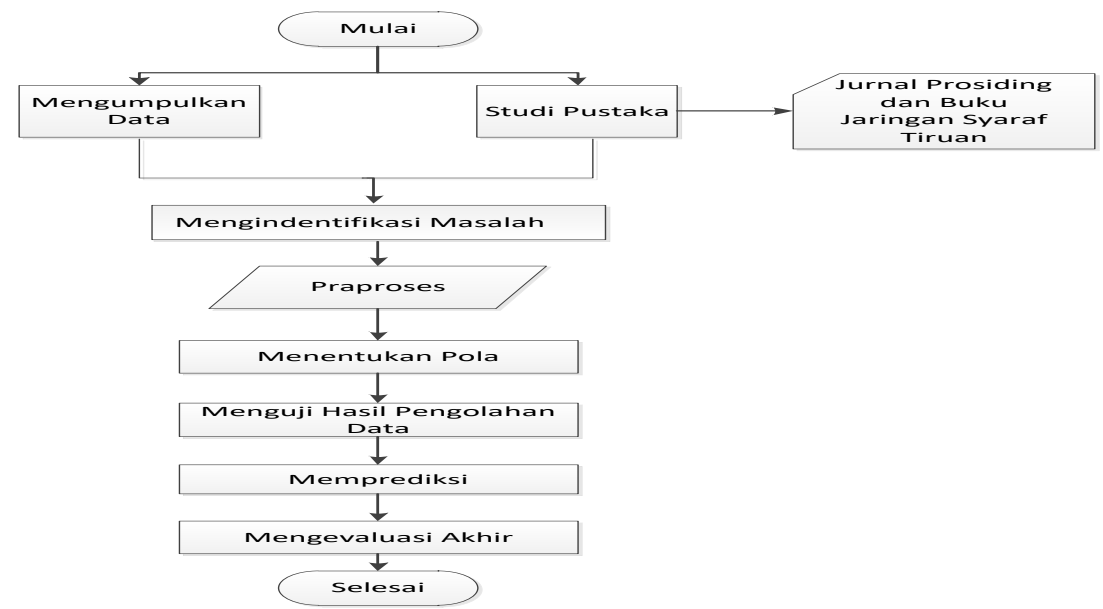

Gambar 1. Kerangka Kerja Penelitian

Penguraian kerangka kerja antara lain :

Pada tahapan kerangka kerja dilakukan pengumpulan data yang diperoleh dari Sistem Informasi penerimaan mahasiswa baru (PMB) AMIK-STIKOM Tunas Bangsa Pematangsiantar tahun 2014-2018. Setelah data diperoleh dilakukan identifikasi masalah. Sementara dalam penelitian dibutuhkan referensi dasar mengenai jaringan syaraf tiruan backpropagation yang banyak diambil dari jurnal-jurnal sebelumnya dan buku jaringan syaraf tiruan backpropagation. Selanjutnya dilakukan tahap selanjutnya sampai dengan pengujian hasil pengolahan data dengan menguji coba melalui software Matlab R2011b (7.13).

Dan sampai pada tahap evaluasi akhir dilakukan bertujuan untuk mengetahui apakah hasil sesuai dengan yang diharapkan.

\subsection{Data Yang Digunakan}

Data yang digunakan adalah data jumlah mahasiswa baru AMIK-STIKOM Tunas Bangsa Pematangsiantar 2014-2018. Data training menggunakan data tahun 2014-2016 dan 2017 sebagai target. Sedangkan data testing menggunakan data tahun 2015-2017 dan 2018 sebagai target.

Tabel 1. Data Jumlah Mahasiswa Baru AMIK-STIKOM (2014-2018)

\begin{tabular}{|l|l|l|l|l|l|l|}
\hline No & Nama Jurusan & $\mathbf{2 0 1 4}$ & $\mathbf{2 0 1 5}$ & $\mathbf{2 0 1 6}$ & $\mathbf{2 0 1 7}$ & $\mathbf{2 0 1 8}$ \\
\hline 1 & Sistem Informasi ( SI ) & 75 & 221 & 200 & 223 & 209 \\
\hline 2 & Teknik Informatika ( TI ) & 0 & 115 & 122 & 145 & 145 \\
\hline 3 & Manajemen Informatika (MA) & 396 & 189 & 171 & 121 & 160 \\
\hline 4 & Komputerisasi Akuntansi (KA) & 162 & 97 & 60 & 60 & 40 \\
\hline
\end{tabular}

\subsection{Normalisasi Data}

Normalisasi terhadap data dilakukan agar keluaran jaringan sesuai dengan fungsi aktivasi yang digunakan. Data-data tersebut dinormalisasi dengan interval [0,1] [15]-[22], [5], [23]-[27]. 


$$
x^{\prime}=\frac{0,8(x-a)}{b-a}+0,1
$$

Keterangan : $x^{f}$ : data yang telah ditransformasi

$$
\begin{aligned}
& x \text { : data yang akan dinormalisasi } \\
& a \text { : data minimun } \\
& b \text { : data maksimun }
\end{aligned}
$$

Tabel 2. Data Pelatihan Awal (2014-2016/2017)

\begin{tabular}{|l|l|l|l|l|l|}
\hline No & Nama Jurusan & $\mathbf{2 0 1 4}$ & $\mathbf{2 0 1 5}$ & $\mathbf{2 0 1 6}$ & $\mathbf{2 0 1 7}$ \\
\hline 1 & Sistem Informasi & 75 & 221 & 200 & 223 \\
\hline 2 & Teknik Informatika & 0 & 115 & 122 & 145 \\
\hline 3 & Manajemen Informatika & 396 & 189 & 171 & 121 \\
\hline 4 & Komputerisasi Akuntansi & 162 & 97 & 60 & 60 \\
\hline
\end{tabular}

Tabel 3. Data Pelatihan Setelah Normalisasi (2014-2016/2017)

\begin{tabular}{|l|l|l|l|l|l|}
\hline No & Nama Jurusan & $\mathbf{2 0 1 4}$ & $\mathbf{2 0 1 5}$ & $\mathbf{2 0 1 6}$ & $\mathbf{2 0 1 7}$ \\
\hline 1 & Sistem Informasi ( SI ) & 0,25152 & 0,54646 & 0,50404 & 0,55051 \\
\hline 2 & Teknik Informatika ( TI ) & 0,10000 & 0,33232 & 0,34646 & 0,39293 \\
\hline 3 & Manajemen Informatika ( MA ) & 0,90000 & 0,48182 & 0,44545 & 0,34444 \\
\hline 4 & Komputerisasi Akuntansi ( KA ) & 0,42727 & 0,29596 & 0,22121 & 0,22121 \\
\hline
\end{tabular}

Tabel 4. Data Pelatihan Awal (2015-2017/2018)

\begin{tabular}{|l|l|l|l|l|l|}
\hline No & Nama Jurusan & $\mathbf{2 0 1 5}$ & $\mathbf{2 0 1 6}$ & $\mathbf{2 0 1 7}$ & $\mathbf{2 0 1 8}$ \\
\hline 1 & Sistem Informasi & 221 & 200 & 223 & 209 \\
\hline 2 & Teknik Informatika & 115 & 122 & 145 & 145 \\
\hline 3 & Manajemen Informatika & 189 & 171 & 121 & 160 \\
\hline 4 & Komputerisasi Akuntansi & 97 & 60 & 60 & 40 \\
\hline
\end{tabular}

Tabel 5. Data Pelatihan Setelah Normalisasi (2015-2017/2018)

\begin{tabular}{|l|l|l|l|l|l|}
\hline No & Nama Jurusan & $\mathbf{2 0 1 5}$ & $\mathbf{2 0 1 6}$ & $\mathbf{2 0 1 7}$ & $\mathbf{2 0 1 8}$ \\
\hline 1 & Sistem Informasi ( SI ) & 0,89126 & 0,79945 & 0,90000 & 0,83880 \\
\hline 2 & Teknik Informatika ( TI ) & 0,42787 & 0,45847 & 0,55902 & 0,55902 \\
\hline 3 & Manajemen Informatika ( MA) & 0,75137 & 0,67268 & 0,45410 & 0,62459 \\
\hline 4 & Komputerisasi Akuntansi ( KA ) & 0,34918 & 0,18743 & 0,18743 & 0,10000 \\
\hline
\end{tabular}

\section{HASIL DAN PEMBAHASAN}

\subsection{Analisis}

Untuk mendapatkan hasil sesuai dengan yang diharapkan, harus melewati proses training dan testing yang dimana parameter-parameter sudah ditentukan[28].

Parameter yang diperhatikan dalam inisialisasi jaringan pada jaringan adalah:

$>>$ net $=$ newff(minmax(P),[Hidden,Target],\{'logsig','purelin'\},'traingd');

$>$ net.lw $\{1,1\}$;

$>$ net.b $\{1\}$;

$>$ net.lw $\{2,1\}$;

$>>$ net.b $\{2\}$; 
$>$ net.trainParam.epochs $=100000$;

$>>$ net.trainParam.goal $=0.001$;

$>>$ net.trainParam. $\mathrm{Lr}=0.01$;

$>$ net.trainParam.show $=1000$;

$>>$ net $=$ train(net, $\mathrm{P}, \mathrm{T})$

$>>[a, P f, A f, e, P e r f]=\operatorname{sim}($ net, $P,[],[], T)$

Semua tahapan pelatihan (training) ini akan dilakukan berulang-ulang untuk mendapatkan bobot terbaik dengan error terkecil. Bobot terbaik tersebut akan digunakan untuk melakukan pengujian (testing).

\subsection{Hasil}

Pada penelitian ini, terdapat 5 model arsitektur yang digunakan,diantaranya : Arsitektur 3-12-1, 3-13-1, 3-14-1, 3-15-1, 3-16-1, 3-18-1. Dan antara kelima arsitektur ini diperoleh model arsitektur terbaik dengan keakurasian $75 \%$ yaitu 316-1.

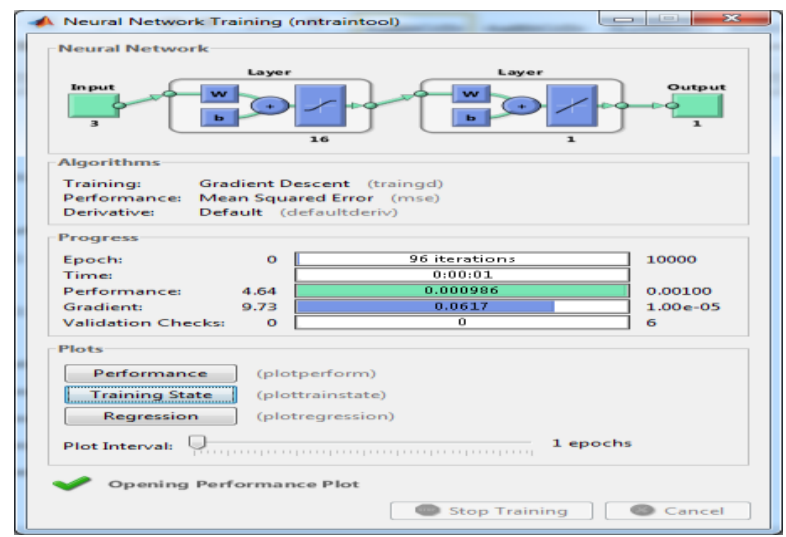

Gambar 2. Hasil Data Pelatihan Dengan Arsitektur 3-16-1

Dari gambar diatas dapat dijelaskan bahwa model arsitektur 3-16-1 merupakan arsitektur terbaik dengan epoch yang terjadi yaitu 96 iterasi dengan waktu yang cukup cepat yaitu 1 detik.

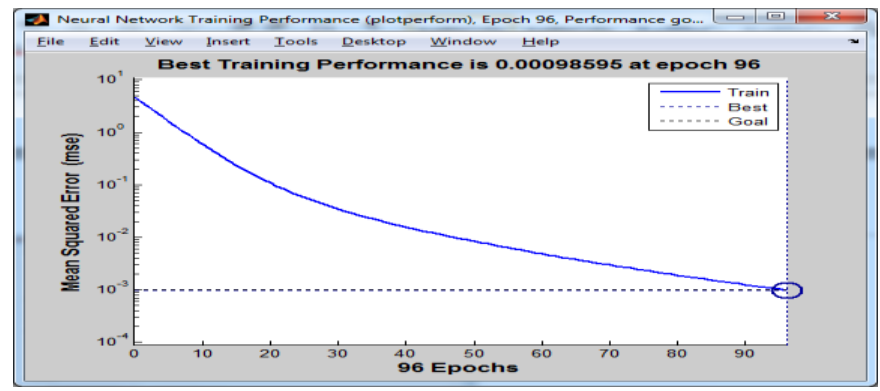

Gambar 3. Hasil Epoch Training Dengan Arsitektur 3-16-1

Dari gambar diatas dapat dijelaskan bahwa Measn Squared Error (MSE) yang diperoleh di epoch 96 pada arsitektur 4-19-1 adalah 0.00098595. 


\begin{tabular}{|c|c|c|c|c|r|c|c|c|c|c|}
\hline \multirow{2}{*}{ No } & \multicolumn{4}{|c|}{ Data Training } & \multicolumn{6}{c|}{ Data Testing } \\
\cline { 2 - 11 } & Target & Output & Error & SSE & No & Target & Output & Error & SSE & Hasil \\
\hline 1 & 0,55051 & 0,51150 & 0,03901 & 0,00152139 & 1 & 0,83880 & 0,97830 & $-0,13950$ & 0,01946086 & 1 \\
\hline 2 & 0,39293 & 0,42090 & $-0,02797$ & 0,00078236 & 2 & 0,55902 & 0,48790 & 0,07112 & 0,00505754 & 0 \\
\hline 3 & 0,34444 & 0,38390 & $-0,03946$ & 0,00155674 & 3 & 0,62459 & 0,93090 & $-0,30631$ & 0,09382572 & 1 \\
\hline 4 & 0,22121 & 0,21240 & 0,00881 & 0,00007765 & 4 & 0,10000 & 1,03900 & $-0,93900$ & 0,88172100 & 1 \\
\hline & & & Jumlah & 0,00393815 & & & & Jumlah & 1,00006512 & 75 \\
\hline & & & MSE & 0,00098454 & & & & MSE & 0,250016279 & \\
\hline
\end{tabular}

Gambar 4. Arsitektur Algoritma Backpropagation

Dari gambar diatas dapat dijelaskan bahwa 1 bernilai benar dan 0 bernilai salah

Tabel 6. Hasil Akurasi Algoritma Backpropagation

\begin{tabular}{|l|l|l|l|l|l|l|}
\hline \multirow{2}{*}{ No. } & \multirow{2}{*}{ Arsitektur } & \multicolumn{3}{l}{ Training } & Testing & \\
\cline { 3 - 7 } & & Epoch & Waktu & MSE & MSE & Akurasi \\
\hline 1 & $3-12-1$ & 124 & $00: 02$ & 0,000985498 & 0,555539698 & $25 \%$ \\
\hline 2 & $3-13-1$ & 87 & $00: 01$ & 0,000988527 & 1,026988158 & $50 \%$ \\
\hline 3 & $3-14-1$ & 105 & $00: 01$ & 0,000956010 & 0,020642826 & $75 \%$ \\
\hline 4 & $3-15-1$ & 201 & $00: 02$ & 0,000998765 & 0,467177375 & $50 \%$ \\
\hline 5 & $3-16-1$ & 96 & $00: 01$ & 0,000984537 & 0,250016279 & $75 \%$ \\
\hline 6 & $3-18-1$ & 41 & $00: 00$ & 0,000995683 & 0,234881776 & $50 \%$ \\
\hline
\end{tabular}

Berdasarkan Tabel 6 dapat dijelaskan bahwa dari keenam arsitektur yang digunakan diperoleh 1 model arstitektur terbaik dengan akurasi $75 \%$ dalam waktu 1 detik.

Tabel 7. Hasil Prediksi 4 Tahun Kedepan Dengan Backpropagation (2019-2022)

\begin{tabular}{|l|l|l|l|l|l|}
\hline No & Nama Jurusan & $\mathbf{2 0 1 9}$ & $\mathbf{2 0 2 0}$ & $\mathbf{2 0 2 1}$ & $\mathbf{2 0 2 2}$ \\
\hline 1 & Sistem Informasi ( SI ) & 205 & 186 & 162 & 140 \\
\hline 2 & Teknik Informatika ( TI ) & 132 & 120 & 117 & 106 \\
\hline 3 & Manajemen Informatika ( MA ) & 145 & 147 & 123 & 110 \\
\hline 4 & Komputerisasi Akuntansi (KA ) & 47 & 53 & 65 & 82 \\
\hline
\end{tabular}

\section{KESIMPULAN}

Kesimpulan yang dapat diambil dari penelitian ini antara lain :

a. Berdasarkan hasil yang diperoleh, algoritma backpropagation cukup efektif dalam memprediksi jumlah mahasiswa baru dengan data record yang ada.

b. Berdasarkan serangkaian model arsitektur yang diuji yakni model arsitektur 312-1, 3-13-1, 3-14-1, 3-15-1, 3-16-1, 3-18-1, diperoleh model terbaik yaitu model 3-16-1 dengan tingkat akurasi $75 \%$, epoch 96 iterasi dalam waktu 1 detik.

c. Berdasarkan penelitan yang sudah dilakukan penulis, untuk memperoleh hasil yang diingikan data yang ada akan diuji menggunakan software Matllab R2011b dengan serangkaian model arsitektur yang sudah ditentukan. 


\section{DAFTAR PUSTAKA}

[1] R. E. Indrajit and R. Djokopranoto, "Manajemen Perguruan Modern," in Manajemen Perguruan Tinggi Modern, 2016.

[2] A. Wanto and A. P. Windarto, "Analisis Prediksi Indeks Harga Konsumen Berdasarkan Kelompok Kesehatan Dengan Menggunakan Metode Backpropagation,” Jurnal \& Penelitian Teknik Informatika Sinkron, vol. 2, no. 2, pp. 37-44, 2017.

[3] A. Wanto, A. P. Windarto, D. Hartama, and I. Parlina, "Use of Binary Sigmoid Function And Linear Identity In Artificial Neural Networks For Forecasting Population Density," International Journal Of Information System \& Technology, vol. 1, no. 1, pp. 43-54, 2017.

[4] A. Wanto, M. Zarlis, Sawaluddin, and D. Hartama, "Analysis of Artificial Neural Network Backpropagation Using Conjugate Gradient Fletcher Reeves in the Predicting Process," Journal of Physics: Conference Series, vol. 930, no. 1, pp. 1-7, 2017.

[5] I. S. Purba and A. Wanto, "Prediksi Jumlah Nilai Impor Sumatera Utara Menurut Negara Asal Menggunakan Algoritma Backpropagation,” Jurnal Teknologi Informasi Techno, vol. 17, no. 3, pp. 302-311, 2018.

[6] S. P. Siregar and A. Wanto, "Analysis of Artificial Neural Network Accuracy Using Backpropagation Algorithm In Predicting Process (Forecasting)," International Journal of Information System \& Technology, vol. 1, no. 1, pp. 34-42, 2017.

[7] J. R. Saragih, M. Billy, S. Saragih, and A. Wanto, "Analisis Algoritma Backpropagation Dalam Prediksi Nilai Ekspor (Juta USD)," Jurnal Pendidikan Teknologi dan Kejuruan, vol. 15, no. 2, pp. 254-264, 2018.

[8] E. Hartato, D. Sitorus, and A. Wanto, "Analisis Jaringan Saraf Tiruan Untuk Prediksi Luas Panen Biofarmaka di Indonesia," Jurnal semanTIK, vol. 4, no. 1, pp. 49-56, 2018.

[9] S. Setti and A. Wanto, "Analysis of Backpropagation Algorithm in Predicting the Most Number of Internet Users in the World," JOIN (Jurnal Online Informatika), vol. 3, no. 2, pp. 110-115, 2018.

[10] R. E. Pranata, S. P. Sinaga, and A. Wanto, "Estimasi Wisatawan Mancanegara Yang Datang ke Sumatera Utara Menggunakan Jaringan Saraf," Jurnal semanTIK, vol. 4, no. 1, pp. 97-102, 2018.

[11] A. A. Fardhani, D. Insani, N. Simanjuntak, and A. Wanto, "Prediksi Harga Eceran Beras Di Pasar Tradisional Di 33 Kota Di Indonesia Menggunakan Algoritma Backpropagation," Jurnal Infomedia, vol. 3, no. 1, pp. 25-30, 2018.

[12] J. Wahyuni, Y. W. Paranthy, and A. Wanto, "Analisis Jaringan Saraf Dalam Estimasi Tingkat Pengangguran Terbuka Penduduk Sumatera Utara,” Jurnal Infomedia, vol. 3, no. 1, pp. 18-24, 2018.

[13] N. Asiyah, "Pola Asuh Demokratis, Kepercayaan Diri dan Kemandirian Mahasiswa Baru," Jurnal Psikologi Indonesia, vol. 2, no. 2, p. 108, 2013.

[14] A. Sudarsono, "Jaringan Syaraf Tiruan Untuk Memprediksi Laju Pertumbuhan Penduduk Menggunakan Metode Backpropagation,” Jurnal Media Infotama, vol. 12, no. 1, pp. 61-69, 2016.

[15] A. Wanto et al., "Levenberg-Marquardt Algorithm Combined with Bipolar Sigmoid Function to Measure Open Unemployment Rate in Indonesia," in Conference Paper, 2018, pp. 1-7.

[16] I. A. R. Simbolon, F. Yatussa'ada, and A. Wanto, "Penerapan Algoritma Backpropagation dalam Memprediksi Persentase Penduduk Buta Huruf di Indonesia," Jurnal Informatika Upgris, vol. 4, no. 2, pp. 163-169, 2018.

[17] S. P. Siregar, A. Wanto, and Z. M. Nasution, "Analisis Akurasi Arsitektur JST Berdasarkan Jumlah Penduduk Pada Kabupaten / Kota di Sumatera Utara," in Seminar Nasional Sains \& Teknologi Informasi (SENSASI), 2018, pp. 526-536.

[18] A. Wanto, "Optimasi Prediksi Dengan Algoritma Backpropagation Dan Conjugate Gradient Beale-Powell Restarts," Jurnal Teknologi dan Sistem Informasi, vol. 3, no. 3, pp. 370-380, Jan. 2018.

[19] B. K. Sihotang and A. Wanto, "Analisis Jaringan Syaraf Tiruan Dalam Memprediksi Jumlah Tamu Pada Hotel Non Bintang," Jurnal Teknologi Informasi Techno, vol. 17, no. 4, pp. 333$346,2018$. 
[20] M. A. P. Hutabarat, M. Julham, and A. Wanto, "Penerapan Algoritma Backpropagation Dalam Memprediksi Produksi Tanaman Padi Sawah Menurut Kabupaten/Kota di Sumatera Utara," Jurnal semanTIK, vol. 4, no. 1, pp. 77-86, 2018.

[21] Y. Andriani, H. Silitonga, and A. Wanto, "Analisis Jaringan Syaraf Tiruan untuk prediksi volume ekspor dan impor migas di Indonesia," Register - Jurnal Ilmiah Teknologi Sistem Informasi, vol. 4, no. 1, pp. 30-40, 2018.

[22] A. Wanto, "Penerapan Jaringan Saraf Tiruan Dalam Memprediksi Jumlah Kemiskinan Pada Kabupaten/Kota Di Provinsi Riau," Kumpulan jurnaL Ilmu Komputer (KLIK), vol. 5, no. 1, pp. 61-74, 2018.

[23] A. Wanto, "Prediksi Angka Partisipasi Sekolah dengan Fungsi Pelatihan Gradient Descent With Momentum \& Adaptive LR," Jurnal Ilmu Komputer dan Informatika (ALGORITMA), vol. 3, no. 1, pp. 9-20, 2019.

[24] N. Nasution, A. Zamsuri, L. Lisnawita, and A. Wanto, "Polak-Ribiere updates analysis with binary and linear function in determining coffee exports in Indonesia," IOP Conference Series: Materials Science and Engineering, vol. 420, no. 12089, pp. 1-9, 2018.

[25] A. Wanto, "Prediksi Produktivitas Jagung Indonesia Tahun 2019-2020 Sebagai Upaya Antisipasi Impor Menggunakan Jaringan Saraf Tiruan Backpropagation," SINTECH (Science and Information Technology), vol. 1, no. 1, pp. 53-62, 2019.

[26] B. Febriadi, Z. Zamzami, Y. Yunefri, and A. Wanto, "Bipolar function in backpropagation algorithm in predicting Indonesia's coal exports by major destination countries," IOP Conference Series: Materials Science and Engineering, vol. 420, no. 12089, pp. 1-9, 2018.

[27] A. Wanto et al., "Analysis of Standard Gradient Descent with GD Momentum And Adaptive LR for SPR Prediction," 2018, pp. 1-9.

[28] R. A. Pratama, "Peramalan Beban Listrik Jangka Panjang Provinsi D.I. Yogyakarta Menggunakan Neural Network Backpropagation," Jurnal Teknik Elektro, vol. 5, no. 3, pp. 1$11,2016$. 